\title{
Load-Displacement Curves of Spot Welded, Bonded, and Weld-Bonded Joints for Dissimilar Materials and Thickness
}

\author{
E.A. Al-Bahkali \\ Department of Mechanical Engineering, College of Engineering, King Saud University, P.O. Box 800, Riyadh 11421, \\ Saudi Arabia
}

Received 15 April 2011; accepted 21 September 2011

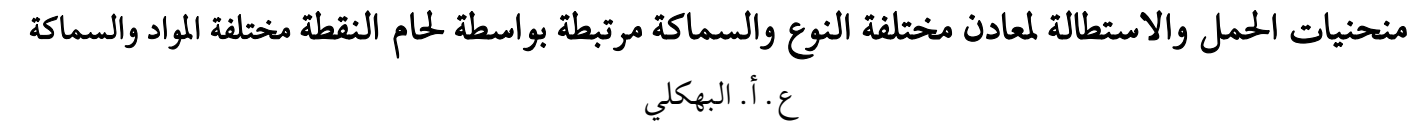

\begin{abstract}
Three-dimensional finite element models of spot welded, bonded and weld-bonded joints are developed using ABAQUS software. Each model consists of two strips with dissimilar materials and thickness and is subjected to an axial loading. The bonded and weld-bonded joints have specific adhesive thickness. A detailed experimental plan to define many properties and quantities such as, the elastic - plastic properties, modulus of elasticity, fracture limit, and properties of the nugget and heat affected zones are carried out. Experiments include standard testing of the base metal, the adhesive, the nugget and heat affected zone. They also include employing the indentation techniques, and ductile fracture limits criteria, using the special notch tests. Complete load-displacement curves are obtained for all joining models and a comparison is made to determine the best combination.
\end{abstract}

Keywords: Spot welding, Adhesive, Weld-bonded, Finite element modelling, Dissimilar material

\section{Introduction}

Resistance Spot Welding (RSW) has been used for decades as a joining method for sheet metal. Weldbonded is a combination of resistance spot welding and adhesive bonding, which has gathered wide acceptance as an effective joining method for significant enhancement of static, dynamic and impact resistance of the joint. It also improves the corrosion and noise resistance as well as stiffness of the joint, com

$\overline{\text { *Corresponding author e-mail: ebahkali@ksu.edu.sa }}$ pared to those observed in case of conventional resistance spot welding. Industrial applications such as automobile and aerospace are good examples of using weld-bonded process.

In order to reach an optimum welding quality of a spot welded or a weld-bonded joints, different calibration trials must be conducted to setup the optimum welding parameters, i.e. welding current, electrode force, and welding time (Bouyousfi et al. 2007, Farukawa et al. 2006). 
Various techniques have been used to analyze the spot welded and weld-bonded joints. Finite element method (FEM) is one of these techniques, which has received a wide acceptance among researchers as a tool for modelling and analysis of welding joints. It has the capability to predict stress distribution, stress concentration, and failure modes for both weld-bonded and spot welded nuggets. To model real joint connection using FE, the elastic and plastic mechanical properties of the parts must be taken into consideration. Therefore, many researchers worked on weldbonded technology experimentally and numerically in an attempt to represent real joint connection. Kang et al. (2006) used Tabor-equation to transform the indentation data to true stress-strain values. More sophisticated methods to determine the elastic-plastic properties from indentation are used and reported by (Venkatesh et al. 2000 and Dao et al. 2001). They used instrumented sharp indentation machine, where the load and displacement during indentation were recorded continuously. Li et al. (2005) studied numerically the deformation and fracture initiation of mode I (normal strength and toughness) in adhesive bonding. Later, Yang et al. (2001) investigated the fracture toughness data for adhesive. In addition, (Li et al. 2006) continued the study of the mixed mode cohesive-zone models for fracture of an adhesively bonded polymer-matrix composite. In their work, the load displacement curve of single lap shear joint obtained by FE analysis showed an acceptable agreement with the experimental data. Moreover, (Cavalli et al. 2004) investigated the finite element model based on cohesive element model for weld-bonded joint of AA-5754 Aluminium alloy.

It is also important to study the microstructure and mechanical properties at the nugget and the heat affected zone (HAZ) caused by welding process because the plastic properties of the nugget and HAZ are different from the base metal. Kong et al. (2008) reported that, the elastic-plastic properties have to be defined for each region of spot welded joint, by the combination of indention and extensive FE simulation of the indentation. Al-Bahkali et al. (2010) have developed a 3D FE model of spot welded, adhesive bonded, and weld bonded joints of austenitic stainless steel sheets of $1.0 \mathrm{~mm}$ thickness. Their models are based on elastic-plastic properties, and ductile fracture limit criteria for steel, whereas the adhesive bonding is modelled based on traction separation. They have also studied the elastic - plastic properties, modulus of elasticity, fracture limit, nugget and HAZ properties. The load-displacement curves obtained from the FE models are in agreement with the experimental data.

Spot weld and weld-bonding of dissimilar materials are of interest to engineers and scientists for efficiently joining two different materials. Hasanbasoglu and Kacar (2007) investigated the influence of the primary welding parameters on the morphology, microhardness, and shear tensile load bearing capacity of two dissimilar steel welds. Darwish (2004) analyzed spot-welded and weld-bonded of dissimilar material joints using FEM. He showed that the stresses were more concentrated towards the member that had the lowest melting point of the joint. He pointed that, adding an adhesive layer in combination with the spot weld resulted in eliminating the stress concentration and strength ending dissimilar material joints.

The aim of present work is to study the load-displacement curves toward the best combination for spot weld, bonded, and weld-bonded for dissimilar materials and thicknesses. 3D FE models are developed for dissimilar spot welded, bonded, and bond-welded joints, based on elastic-plastic properties and ductile fracture limit criteria for each region (base metal, nugget and HAZ). These developed FE models can predict the deformation and fracture initiation, including the maximum load of the weld-bonded joint as well as spot welded and adhesive bonded for any combination of sheet thickness, overlap area, and nugget diameter. In the FE models, the plastic properties of each welding region are defined by spherical indentation and transformed to true stress-true strain using Ahn-equation 2006. Furthermore, the ductile fracture limit criteria are employed to determine the fracture initiation point in the FE model (Bao 2005; Mackenzie et al. 1977; Hancock, Mackenzie 1976). This method is based on evaluating the stress triaxiality versus equivalent plastic strain conditions. The fracture limits of adhesive bonding are introduced in terms of maximum normal stress and shear stress of traction separation, which is defined experimentally (Sun et al. 2009, Diehl 2005).

\section{Finite Element Model}

\subsection{Geometry}

In this section, three different finite elements models are considered. These models are a single lap bonded model, a single lap spot weld model, and a single lap weld-bonded model. Figure 1 shows the front view (F.V) and top view (T.V) configurations, dimensions, constraints and loading conditions for bonded and weld-bonded models. Spot weld model is similar to weld-bonded except that it does not have an adhesive layer around the nugget. The total length of each model is $175 \mathrm{~mm}$. The strips thicknesses are $1 \mathrm{~mm}$ and $1.5 \mathrm{~mm}$, respectively.

The following assumptions are considered throughout the idealization process. The models are threedimensional and because of symmetry half of the model is considered to save computation time. The 


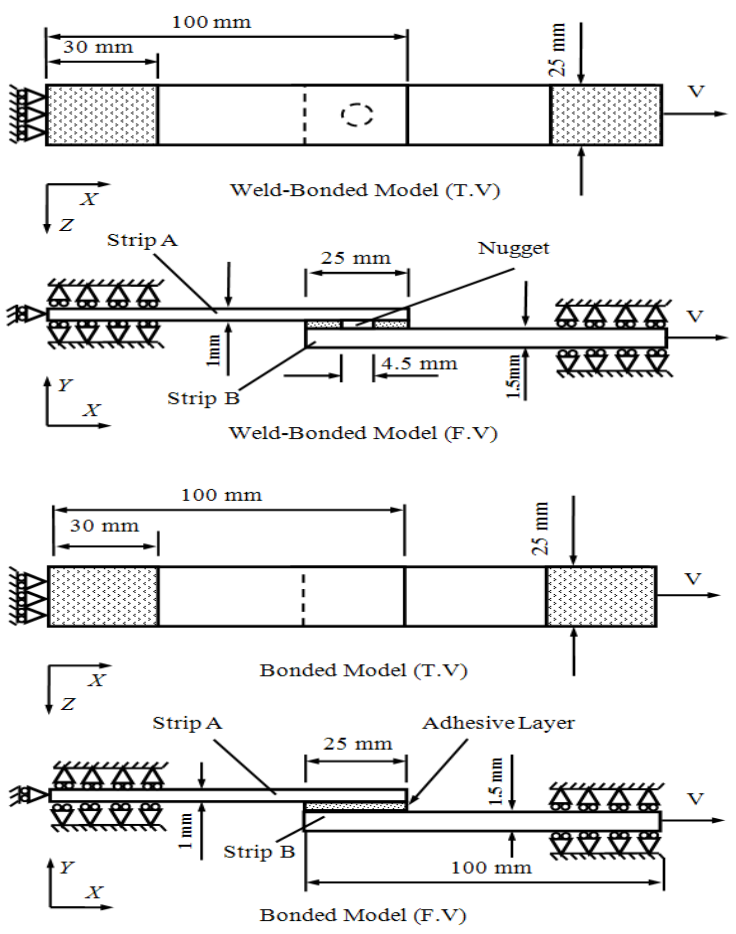

Figure 1. Bonded and weld-bonded models

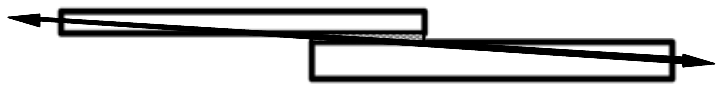

(a)

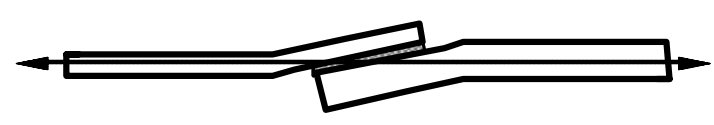

(b)

Figure 2. Lap-joint have (a) a line of action is not initially parallel to the adhesive layer, (b) the overlap area bends as load increses

adhesive layer is isotropic and has a thickness of 0.12 $\mathrm{mm}$. There is no adhesive layer in a zone $1 \mathrm{~mm}$ around the circumference of the weld nugget and the depth of the indentation is assumed to be $0.1 \mathrm{~mm}$ for both strips (Baohua et al. 2001). This indentation caused by the electrode of the spot weld machine. All the regions in the FE modeling were connected by sharing nodes. The overlap joint is subjected to a constant velocity of $1 \mathrm{~mm} / \mathrm{min}$. The line of action is not initially parallel to the adhesive layer as shown in Fig. 2. As the load increases the overlap area bends. Consequently, the ends of the adhesive layer peel and shear stresses appear. These stresses often induce joint failure.

\subsection{Boundary Conditions}

The boundary conditions associated with each finite element model can be summarized as follows.

On the edges $\mathrm{X}=0$, clamped boundary conditions are imposed,

$$
\left.u_{x}\right|_{x=o}=\left.u_{y}\right|_{x=o}=\left.u_{z}\right|_{x=o}=0
$$

Whereas both strips are subjected to a fixed y-direction boundary condition for $30 \mathrm{~mm}$ segment of strip A $(X=0$ to $30 \mathrm{~mm})$ and at the end $30 \mathrm{~mm}$ segment of strip $\mathrm{B}(X=145$ to $175 \mathrm{~mm})$.

$$
\left.u_{y}\right|_{x=0-30}=\left.u_{y}\right|_{x=145-175}=0
$$

In the overlap area, tie constraints are imposed between components of welded joints; i.e. strip A, strip B, adhesive layer, and weld nugget. By doing so, the translational and rotational boundary conditions of tied surfaces are made identical, regardless of the way these parts are meshed.

The model is subjected to a constant velocity $(\mathrm{V}=1$ $\mathrm{mm} / \mathrm{min}$.) at the right edges of strip B.

$$
\left.V_{x}\right|_{x=175}=1 \mathrm{~mm} / \mathrm{min}
$$

\subsection{Finite Element Mesh}

The finite element computation is carried out using ABAQUS software. The finite-element meshes of these models are generated using eight-node-linear brick reduced integration elements. Figure 3 shows the FE meshes for adhesive model (bonded) and weldbonded models, respectively.

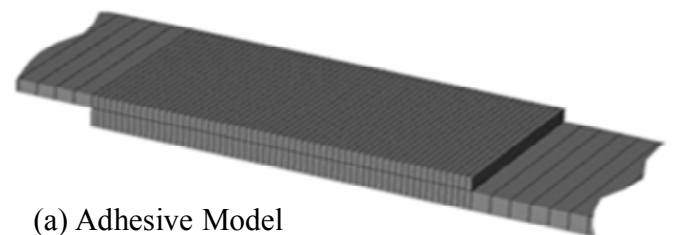

(a) Adhesive Model

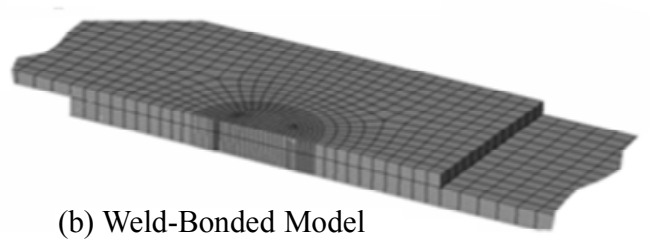

Figure 3. Finite element mesh for both bonded weld-bonded models

The mesh of bonded model is straight forward and simpler because of the absence of spot welding, which leads to only the overlap area that needs to be divided into fine mesh. However, the spot and weld-bonded models need further fine mesh on the edges of spot weld and adhesive layer to reduce modeling errors. The numbers of elements for the different models, after several trials of refined meshes to ensure the conversion of FE results, are given in Table 1.

\section{Results}

\subsection{Material Properties}

The material properties used throughout the present 
work are given in Table 2. These properties were obtained in the laboratory.

Table 1. Elements number used in different models

\begin{tabular}{cccc}
\hline Model & $\begin{array}{c}\text { Bonded } \\
\text { Model }\end{array}$ & $\begin{array}{c}\text { Spot } \\
\text { Model }\end{array}$ & $\begin{array}{c}\text { Weld-Bonded } \\
\text { Model }\end{array}$ \\
\hline $\begin{array}{c}\text { Strip A } \\
\text { 1mm }\end{array}$ & 13582 & 4072 & 4072 \\
$\begin{array}{c}\text { Strip B } \\
1.5 \mathrm{~mm}\end{array}$ & 20292 & 6108 & 6108 \\
$\begin{array}{c}\text { Adhesive } \\
\text { Layer }\end{array}$ & 1891 & --- & 472 \\
Nugget & ----- & 1140 & 1254 \\
\hline
\end{tabular}

Tab le 2. Material properties of strip and adhesive

\begin{tabular}{cccc}
\hline Material & Adhesive & $\begin{array}{c}\text { AISI } \\
304 \\
\text { Steel }\end{array}$ & Brass \\
\hline $\begin{array}{c}\text { Young's } \\
\text { Modulus } \\
\text { E(GPa) } \\
\text { Possion's } \\
\text { Ratio } v\end{array}$ & 1.9 & 193.7 & 105.33 \\
$\begin{array}{c}\text { Yield Stress } \\
\text { S (MPa) } \\
\begin{array}{c}\text { Ultimate } \\
\text { Stress S } \\
\text { (MPa) }\end{array}\end{array}$ & 32 & 277.3 & 255 \\
$\begin{array}{c}\text { Melting Point } \\
\text { ( }{ }^{\circ} \text { C) }\end{array}$ & 60.4 & 729.2 & 407.5 \\
\hline
\end{tabular}

The elastic-plastic properties of the joint are needed for the FE modeling. This requires identifying and determining accurately each region of the spot welded joint, which is achieved by conducting microhardness measurements across the joint specimens. Therefore, Vickers micro-hardness measurements of the weld nugget, HAZ, and base metal of spot welded joints are carried out at a load of 100 gram. The measurements started from the center of the nugget moving outwards step by step to the HAZ then to the base metal, with an incremental distance of $0.25 \mathrm{~mm}$.

Spherical indentation ( $2 \mathrm{~mm}$ diameter) is used to define the plastic properties of the nugget and heat affected zone for only the AISI 304 steel. This is because steel's properties are affected by the heat. However, brass is not affected by the heat during spot welding process. Consequently, the true stress-true strain curves for AISI 304 steel in these regions are derived using Ahn-Equation:

$$
\sigma=\left(\frac{1}{\psi}\right) P_{m}=\left(\frac{1}{\psi}\right)\left(\frac{P}{\mu a_{c}^{2}}\right)
$$

$$
\varepsilon=\left(\frac{\alpha}{\sqrt{1-\left(a_{c} \mid R\right)^{2}}}\right)\left(\frac{a_{c}}{R}\right)
$$

where $\sigma$ is the true stress, $\psi$ is an empirical factor which is equal to 3.6. $P$ is the load, $P_{m}$ is the mean pressure, $a_{c}$ is the contact radius between the indenter and the material, $\varepsilon$ is the true strain, $\alpha$ is the adjustment constant taken as 0.14 (Jeon et al. 2006), and $R$ is the indenter radius. The true stress-true strain curves of the base metal, HAZ, and nugget of spot welded joint for AISI 304 steel are shown in Fig. 4. For the brass, being not affected by heat, the true stress-true strain curves is the same for base metal, HAZ, and nugget of spot welded joint as shown in Fig. 5.

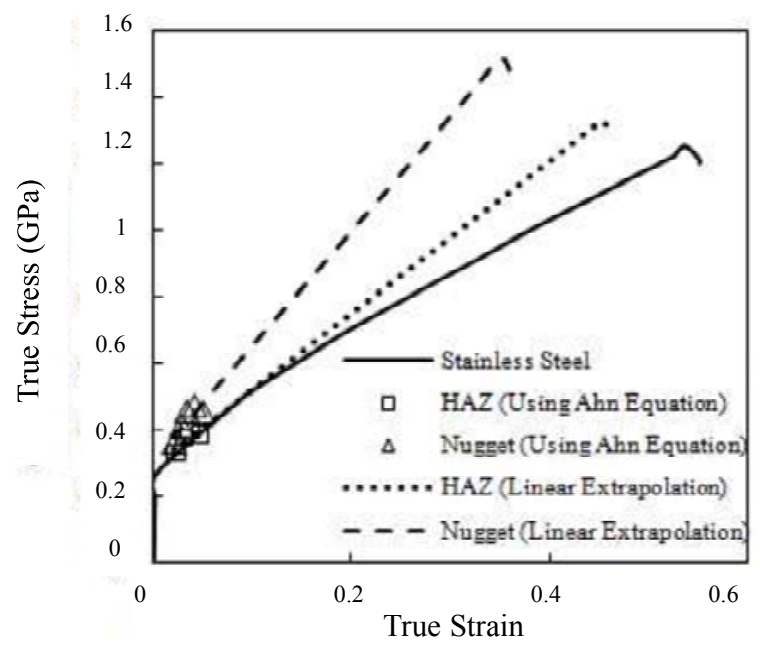

Figure 4. True stress-true strain curves of the base metal, HAZ, and nugget of spot welded joint for AISI 304 steel

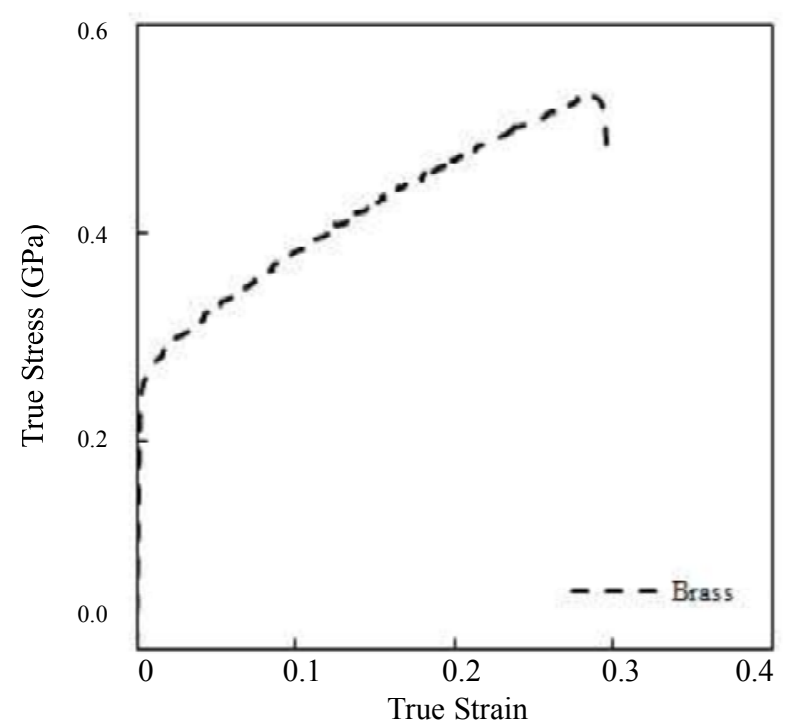

Figure 5. True stress-true strain curves for brass

In order to ensure the micro-hardness results, a micro structure of welding cross section was consid- 


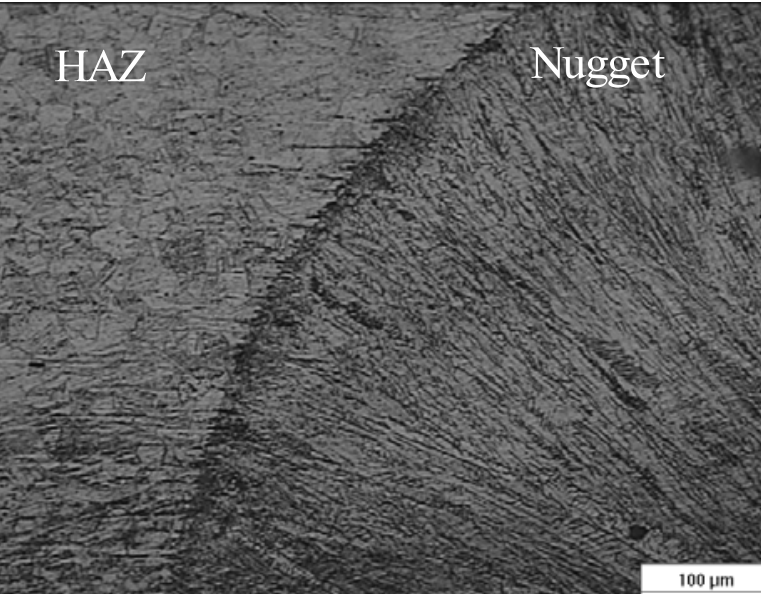

Figure 6. Micro structure of nugget and HAZ for AISI 304 steel

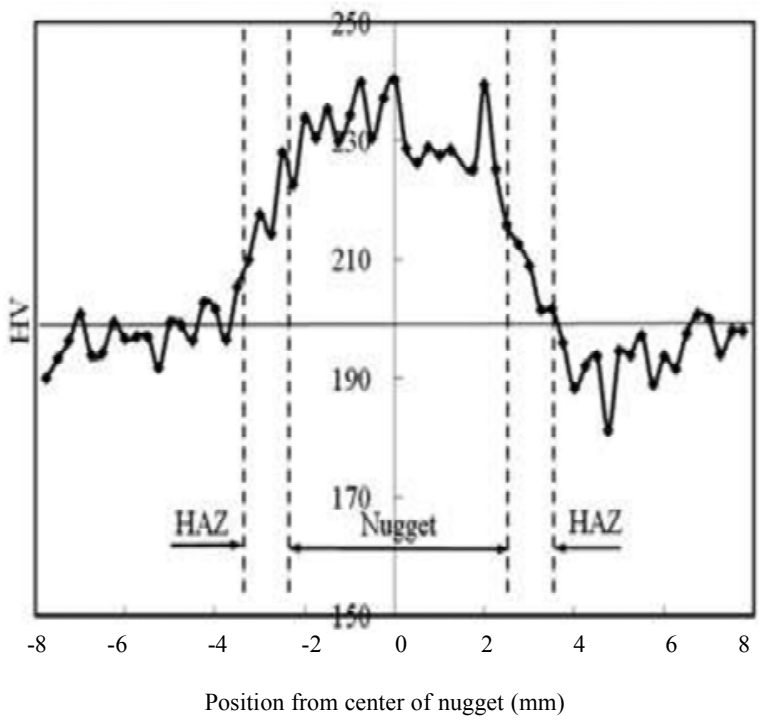

Figure 7. Micro-hardness vickers test results for AISI 304 steel

ered. After grinding and polishing, the specimen was etched by dipping into a solution of $10 \mathrm{ml}$ nitric acid, $10 \mathrm{ml}$ acetic acid, $5 \mathrm{ml}$ glycerin and $15 \mathrm{ml}$ hydrochloric acid, followed by washing in stream of water. Finally, the micro structure was examined for AISI 304 steel using optical microscope as shown in Fig. 6. The micro structure of brass is not changed during the process of spot welding which leads to constant hardness for base metal, HAZ, and nugget areas.

The results of micro-hardness testing for AISI 304 steel are plotted in Fig. 7. It is clear from the figure that the nugget has the highest hardness, followed by the HAZ, and finally the base metal. In addition, the dimension of each region is described clearly in the figure.

To obtain the fracture initiation point (maximum load) as one of the results of finite element modeling, the fracture initiation limits have to be introduced in the model. These properties can be defined and evaluated from the notch tensile test. In ABAQUS software,

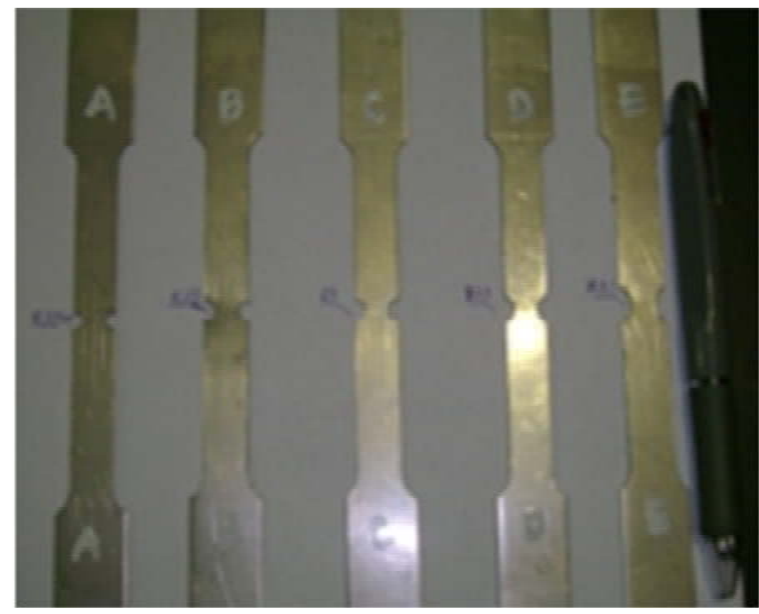

Figure 8. Notched brass specimens prepared for tinsile test

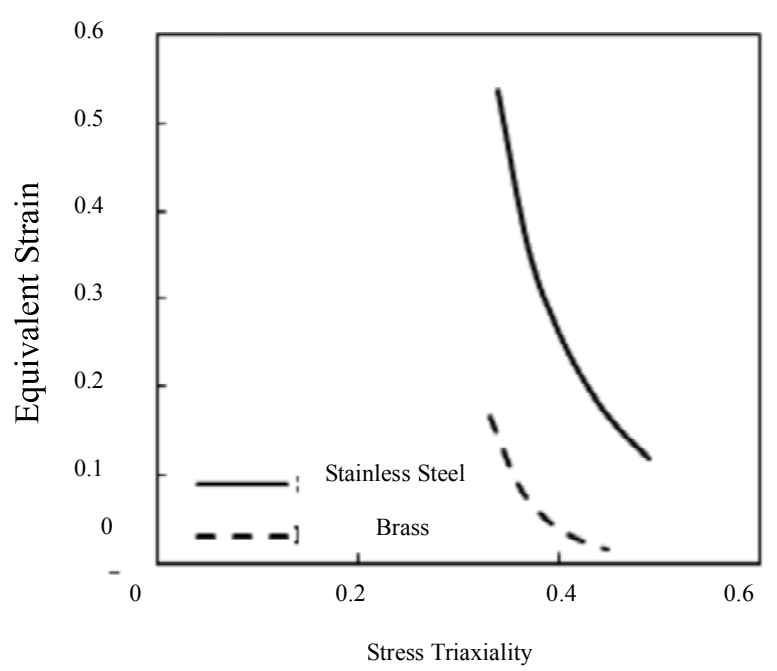

Figure 9. The ductile fracture limit properties

the ductile fracture limits are defined in terms of stress triaxiality and corresponding equivalent fracture strain. The basic theories of the stress triaxiality are described in references (Bao 2005; Mackenzie et al. 1977; Hancock, Mackenzie 1976).

Mackenzie et al. (1977) defined the stress triaxiality for cylindrical specimen as:

$$
\sigma_{\text {Triaxiality }}=\sigma_{m} / \sigma^{\prime}
$$

where $\sigma_{m}$ is the mean principal stress, and it is defined as:

$$
\sigma_{\mathrm{m}}=\left(\sigma_{1}+\sigma_{2}+\sigma_{3}\right) / 3
$$

and $\sigma^{\prime}$ is the effective stress which is defined as:

$$
\sigma^{\prime}=\left[1 / 2\left\{\left(\sigma_{1}-\sigma_{2}\right)^{2+}+\left(\sigma_{2}-\sigma_{3}\right)^{2+}+\left(\sigma_{3}-\sigma_{1}\right)^{2}\right\}\right]^{1 / 2}
$$

where $\sigma_{1}, \sigma_{2}$, and $\sigma_{3}$ are the principal stresses. 
In order to obtain the stress triaxiality and its corresponding equivalent fracture strain values for sheet specimen, notch tensile specimens were prepared and tested according to the standard tensile test. Five notch specimens were prepared with notch radii of 2 , $2.5,3,4$, and $5.1 \mathrm{~mm}$, respectively, for each material. Figure 8 shows a picture of notched brass specimens before subjected to tensile test.

Standard tensile tests were conducted on each samples as stated above, a complete load displacement curve is obtained from the tests. The equivalent true strains at the fracture initiation were calculated automatically using the Bluehill-software. Then, the stress triaxiality at the determined equivalent strain was calculated numerically using ABAQUS software.

The stress triaxiality values and the corresponding equivalent fracture strains for AISI 304 steel and brass are plotted in the Fig. 9. The data were extrapolated as an exponential curve, based on a recommendation of previous researchers (Bao 2005; Mackenzie et al. 1977; Hancock, Mackenzie 1976).

The adhesive layer model is developed based on traction separation mode. After defining all materials properties, the FE models are run to obtain the loaddisplacement curves.

\subsection{Finite Element Results}

In this section, the results of the finite element simulations for bonded, spot weld, and weld-bonded dissimilar materials and thickness joints are examined. The combination dissimilar materials used in the analysis are steel-brass. In the first combination, the material for strip A is steel with $1 \mathrm{~mm}$ thickness while the material for strip B is brass with $1.5 \mathrm{~mm}$ thickness. In the second combination, strip A represents steel with $1.5 \mathrm{~mm}$ thickness while strip B represents brass with $1 \mathrm{~mm}$ thickness.

Figure 10 shows three different load-displacement curves for joining steel (1 mm thickness) with brass (1.5 mm thickness). When both materials are joined by spot weld, the joint can withstand a maximum load of $4 \mathrm{kN}$ at a displacement of $0.39 \mathrm{~mm}$. When they are joined by adhesive, the load reaches $9.9 \mathrm{kN}$ and the displacement reaches $1.08 \mathrm{~mm}$. Adding an adhesive layer to the spot weld, the maximum load is slightly increased to $10 \mathrm{kN}$ and the displacement is increased to $1.28 \mathrm{~mm}$.

Figure 11 shows three different load-displacement curves for joining steel (1.5 mm thickness) with brass (1mm thickness). When the materials are joined by spot weld, the joint can hold up to a maximum load of $3.8 \mathrm{kN}$ at a displacement of $0.29 \mathrm{~mm}$. When they are joined by adhesive, the load reaches $7.79 \mathrm{kN}$ and the displacement reaches $0.94 \mathrm{~mm}$. Adding an adhesive layer to the spot weld, the maximum load is almost the

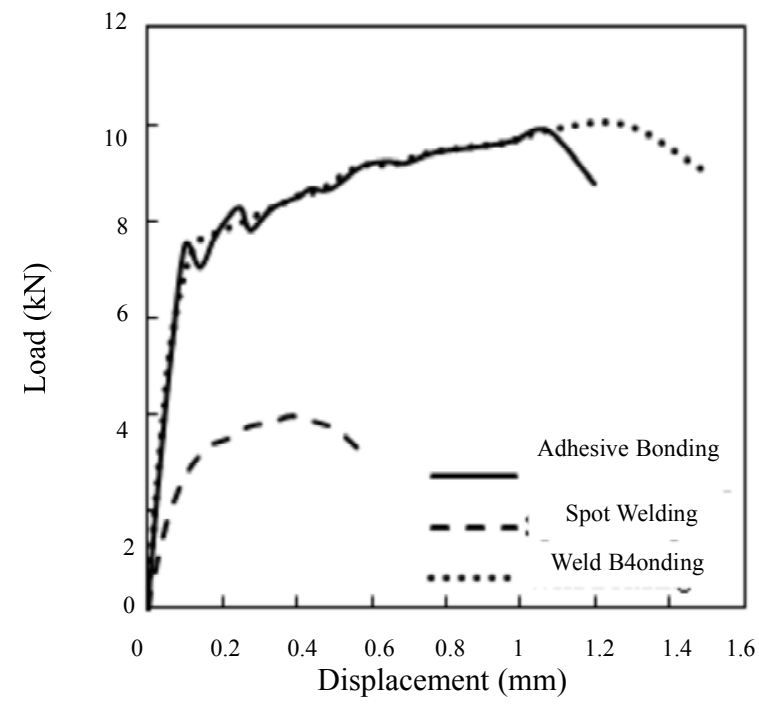

Figure 10. Load displacement curves for joining steel (1 mm thickness) with brass (1.5 $\mathrm{mm}$ thickness)

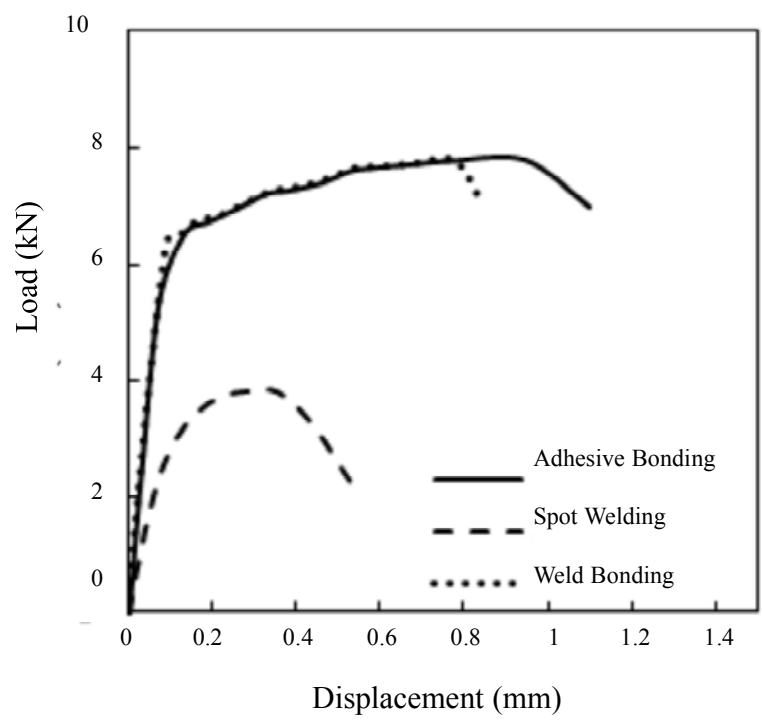

Figure 11. Load displacement curves for joining steel (1.5 mm thickness) with brass (1 mm thickness)

same at $7.78 \mathrm{kN}$. However, the displacement is reduced to $0.78 \mathrm{~mm}$

Figure 11. Load displacement curves for joining steel (1.5 mm thickness) with brass (1 mm thickness) The maximum load $(\mathrm{P} \mathrm{kN})$ and corresponding displacement $(\delta \mathrm{mm})$ obtained from both Figs. 10 and 11 can be summarized in Table 3. The results show that when the thinner strip is steel, the weld-bonded model can withstand larger load and longer extension. In case the thinner strip is brass, both bonded and weld-bonded models have almost the same maximum load, however, bonded model has longer extension. 
Table 3. Maximum load-displacement for different models combinations

\begin{tabular}{ccccccc}
\hline \multirow{2}{*}{$\begin{array}{c}\text { Model } \\
\text { Combin } \\
\text { ation }\end{array}$} & \multicolumn{2}{c}{ Spot } & \multicolumn{2}{c}{ Bonded } & \multicolumn{3}{c}{$\begin{array}{c}\text { Weld- } \\
\text { Bonded }\end{array}$} \\
\cline { 2 - 7 } & $\begin{array}{c}\mathrm{P} \\
\mathrm{kN}\end{array}$ & $\begin{array}{c}\delta \\
\mathrm{mm}\end{array}$ & $\begin{array}{c}\mathrm{P} \\
\mathrm{kN}\end{array}$ & $\begin{array}{c}\delta \\
\mathrm{mm}\end{array}$ & $\begin{array}{c}\mathrm{P} \\
\mathrm{kN}\end{array}$ & $\begin{array}{c}\delta \\
\mathrm{mm}\end{array}$ \\
\hline $\begin{array}{c}\text { Steel } \\
1.0 \mathrm{~mm}\end{array}$ & & & & & & \\
$\begin{array}{c}\text { Brass } \\
1.5 \mathrm{~mm} \\
\text { Steel }\end{array}$ & 4 & 0.39 & 9.9 & 1.08 & 10 & 1.28 \\
$1.5 \mathrm{~mm}$ \\
$\begin{array}{c}\text { Brass } \\
1.0 \mathrm{~mm}\end{array}$ & 3.8 & 0.29 & 7.79 & 0.94 & 7.78 & 0.78 \\
\hline
\end{tabular}

\section{Conclusions}

A three-dimensional finite element model for dissimilar materials and thickness are developed. This includes the 3-D finite element modeling of the spot welded, bonded and weld-bonded joints under axial loading conditions. The combinations of dissimilar materials that are used in the analysis are steel-brass. In the first combination, steel is thinner than brass while in the other combination, the brass is thinner than the steel. For each combination, the load-displacement curves for all three joining types are successfully obtained.

When the thinner strip is steel, the bonded model is 2.47 times better than spot model in terms of load carrying capacity. Adding the adhesive layer to the spot model will result in a very small improvement in maximum load bearing capacity. However, the displacement is improved by $15.63 \%$. When the thinner strip is brass, both bonded and weld-bonded models have almost the same maximum load, however, it is better to use the bonded model because the displacement in bonded is more than the weld-bonded by $20.5 \%$. In general, for a model with dissimilar materials and thickness, it is better to use the weld-bonded model when the strip of the softer material has the large thickness and to use the bonded model when the strip of the harder material is thick.

\section{Acknowledgments}

The author is grateful for the College of Engineering Research Center at King Saud University, for the support of this work (Project No. 19/428).

\section{References}

Al-Bahkali E, Es-Saheb M, Herwan J (2010), Finite element modeling of weld-bonded joint. The $4^{\text {th }}$ Int. Conf. on Advanced Computational Engineering and Experimenting, Paris, France.
Bao Y (2005), Dependence of ductile crack formation in tensile tests on stress triaxiality stress and strain ratios. J. of Engineering Fracture Mechanics 72: 502-522.

Baohua C, Yaowu S, Liangqing L (2001), Studies on the stress distribution and fatigue behavior of weld-bonded lap shear joints. J. of Materials Processing Technology 108:307-313.

Bouyousfi B, Sahraoui T, Guessasma S, Chaoch K (2007), Effect of process parameter on the physical characteristic of spot weld joints. J. of Materials and Design 28:414-419.

Cavalli M, Thouless M, Yang Q (2004), Cohesivezone modeling of the deformation and fracture of weld-bonded joints. Welding Journal 133-139.

Dao M, Chollacoop N, Van Vliet KJ, Venkatesh TA, Suresh S (2001), Computational modeling of forward and reverse problems in instrumented sharp indentation. Acta Materialia 49:3899-3918.

Darwish S (2004), Analysis of weld-bonded dissimilar materials. Int. J. of Adhesion and Adhesives 24: $347-354$

Diehl T (2005), Modeling surface-bonded structures with ABAQUS cohesive elements: beam-type solution. ABAQUS User's Conference.

Furukawa K, Katoh M, Nishio K, Yamaguchi T (2006), Influence of electrode pressure and welding conditions on the maximum tensile shear load. Q, J. of the Japan Welding Society 10-16.

Hancock JW, Mackenzie AC (1976), On the mechanism of ductile failure in high-strength steels subjected to multi-axial stress-states. J. of the Mechanics and Physics of Solids 24:147-169.

Hasanbasoglu A, Kacar R (2007), Resistance spot welding of dissimilar materials (AISI 316L-DIN EN 10130-99). J. of Materials and Design 28:1794-1800.

Jeon E, Kim JY, Baik MK, Kim SH, Park JS, Kwon D (2006), Optimum definition of true strain beneath a spherical indenter for deriving indentation flow curves. J. of Materials Science and Engineering A419:196-201.

Kang BSJ, Yao Z, Barbero EJ (2006), Post-yielding stress-strain determination using spherical indentation. Mechanics of Advanced Materials and Structures 13(2):129-138.

Kong X, Yang Q, Li B, Rothwell G, English R, Ren $H$ (2008), Numerical study of spot-welded joints of steel. J. of Materials and Design 29:1554-1561.

Li S, Thouless MD, Waas AM, Schroeder JA, Zavattieri PD (2005), Use of mode I cohesive zone models to describe the fracture of an adhesively-bonded polymer-matrix composite. J. of Composite Science and Technology 65:281-293.

Li S, Thouless MD, Waas A.M, Schroeder JA, Zavattieri PD (2006), Mixed-mode cohesive-zone 
models for fracture of an adhesively bonded polymer-matrix composite. J. of Engineering Fracture Mechanics 73:64-78.

Mackenzie AC, Hancock JW, Brown DK (1977), On the influence of state of stress on ductile failure Initiation in high strength steels. J. of engineering fracture mechanics 9:167-188.

Sun C, Thouless MD, Waas AM, Schroeder J, Zavattieri PD (2009), Rate effects for mixed-mode fracture of plastically-deforming adhesively- bonded structures. Int. J. of Adhesion and Adhesives 29:434-443.

Venkatesh TA, Van Vliet KJ, Giannakopoulos AE, Suresh S (2000), Determination of elasto-plastic properties by instrumented sharp indentation: guidelines for property extraction. Scripta Materialia 42:833-839.

Yang QD, Thouless MD, Ward SM (2001), Elasticplastic mode II fracture of adhesive koints. International Journal of Solid Structure 38:32513262. 